\title{
ECOLOGY OF ORCHIDS IN URBAN BUSHLAND RESERVES - CAN ORCHIDS BE USED AS INDICATORS OF VEGETATION CONDITION?
}

\author{
Belinda J. Newman ${ }^{1,2,4}$, PhIL LAdD $^{1}$, Andrew BatTy $^{3} \&$ Kingsley DiXon $^{2}$ \\ ${ }^{1}$ Division of Science and Engineering, School of Environmental Science, Murdoch University, \\ Murdoch, WA 6150, Australia. \\ ${ }^{2}$ Science Directorate, Botanic Gardens and Parks Authority, Kings Park and Botanic Garden, \\ West Perth, WA 6005, Australia. \\ ${ }^{3}$ School of Earth and Geographical Sciences, Faculty of Natural and Agricultural Sciences, \\ The University of Western Australia, Crawley, WA 6009, Australia. \\ ${ }^{4}$ Author for correspondence: bnewman@bgpa.wa.gov.au
}

KEY WORDS: terrestrial orchid, indicators, urban reserves, vegetation condition, mycorrhiza, pollination

The loss of urban native vegetation is a global crisis particularly as cities continue to expand and populations grow. Native vegetation often remains as small isolated fragments embedded in the human matrix of urban development. These remnants become islands of biodiversity that experience varying degrees of degradation due to their high perimeter to area ratio. Habitat loss in the biodiversity hotspot of south west Western Australia is considered to be one of the major threats to native terrestrial orchids, and is in part responsible for the current listing of 35 species as critically endangered (Western Australian Government 2006). Diminishing habitats and fragmentation of populations by urban development raises questions as to the sustainability of remnant populations. However, despite the loss of habitat, orchids continue to persist in the urban environment although little is known in detail of their ecological response to such pressures. Orchids are a highly specialized group of plants, their pollination methods and mycorrhizal associations ensure complex interactions with their environment. Do these interactions provide a measurable way to assess the health of ecosystems? Six orchid species of varying pollination mechanisms, associated mycorrhiza and growth form are used in this study. Although the study species are common to the Swan Coastal Plain, many are congeners to much rarer species currently under threat of extinction. This study provides insights into orchid ecology by examining pollination rates, mycorrhizal relationships and field plant establishment.
Measurement and quantification of ecological responses of orchids in reference to varying site condition variables aims to determine whether orchids can be successfully utilized as indicators of vegetation condition.

\section{Vegetation Condition Assessment}

There are many disturbances that originate from the surrounding urban matrix including fire, nutrient enrichment and weed invasion. Disturbance in urban bushland remnants impacts upon the general condition and sustainability of the vegetation community. The structure and function of the urban remnant can become compromised and the vegetation may undergo change, the extent of which will be determined by the underlying vigour, resilience and organization of the vegetation (Calow 1995, Hobbs 2001). Various methods of vegetation condition assessment were compared in this study to determine which method may be most suitable for application to urban bushland reserves. The methods investigated include The Habitat Hectares method (Parkes et al. 2003). This method utilizes a benchmark condition against which the condition of other sites is measured. The Viability Estimate developed by Del Marco et al. (2004), which is designed to be used by local government, land managers and trained volunteers, but not necessarily botanical ecologists. It provides a more qualitative determination of vegetation condition based on visual estimation. The final method explored is the Vegetation Condition Index (VCI), developed by Stenhouse (2005) as a quantita- 
tive tool for investigating the effects of anthropogenic disturbance on vegetation condition. The presence of orchids is compared with site rankings based on vegetation condition to determine if there is a relationship between orchid presence and vegetation condition. Further interrogation of the data is carried out to ascertain whether certain orchid species were potential indicator species.

\section{Pollination}

As bushland fragments become more isolated, visitation by pollinators, plant fecundity and population survival diminishes (Hobbs \& Yates 2003). Orchids are dependent on the presence of pollinators for their continued survival. Some orchids are more specific in the cadre of pollinators that repeatedly and successfully provide pollination success. Orchids may provide a pollinator reward, or as is more common in the south west Australian orchids, be a floral deception. Other orchid species are more generalist relying on pollination by foragers or incidental events (Dafni \& Bernhardt 1990). Due to this dependence on pollinators, orchids may be used to provide information on insect communities in the area. Measuring pollination success, by seed set, provides an indication of the general health and condition of the site. This study looked at pollination success over two consecutive years using both hand and natural pollination in order to measure pollination as a response to varying vegetation conditions. Experiments were also conducted to determine if resource limitation was occurring as a result of poor vegetation condition.

\section{Mycorrhiza}

Orchids rely on their mycorrhizal associations in order to germinate and in many species this dependency carries on into adulthood with seasonal reinfection (Rasmussen 2002). Orchids range from the very specific to the more general in relation to the mycorrhiza they play host to. The persistence of the correct fungus species is required for the survival of the orchids. However, soil nutrients, disturbance, soil moisture and litter layer may all influence the distribution of orchid mycorrhiza. Measuring the distribution and presence of the fungi provides insights to the general health and condition of the site. Seven orchid species were used in baiting experiments to determine the potential extent of fungal distribution using ex situ methods and ecological distribution using in situ methods. Correlations with microhabitat and broader scale condition data show potential relationships between habitat and mycorrhizal distribution. Distribution of mycorrhiza in relation to the adult host plant is investigated through an in situ baiting experiment. The identification of many of the mycorrhiza recovered from adult hosts across sites of varying condition is made using the primers ITS1F and ITSR. Genetic sequencing of mycorrhizal isolates allows a thorough investigation of fungal specificity and the influence of environmental conditions on fungal presence.

The complex interactions of orchids with their environment mean they are sensitive to environmental changes. Information may be gained on the general health and condition of the ecosystem by measuring the health and responses of orchid populations, as this study investigates. However, if the use of orchids as indicators proves to be inappropriate, the knowledge on orchid ecology gained from such studies may be invaluable in future planning and management of urban reserves.

ACKNOWLEDGEMENTS. This work was supported by funding from Murdoch University and Botanic Gardens and Parks Authority. The authors would also like to thank the co operation of Botanic Gardens and Parks Authority, City of Wanneroo, City of Joondalup and City of Stirling for access to study sites.

\section{LiTERATURE CITED}

Calow, P. 1995. In: D. Rapport, C. Gaudet \& P. Calow (eds.). Evaluating and Monitoring the Health of LargeScale Ecosystems. Springer - Verlag, Germany.

Dafni, A., \& P. Bernhardt. 1990. Pollination of terrestrial orchids of southern Australia and the Mediterranean region. Evol. Biol. 24: 193-253.

Del Marco, A., R. Taylor, K. Clarke, K. Savage, J. Cullity, \& C. Miles. 2004. Local Government Biodiversity Planning Guidelines for the Perth Metropolitan Region. Western Australian Local Government Association, Perth.

Hobbs, R. 2001. Synergisms among habitat fragmentation, livestock grazing and biotic invasions in south-western 
Australia. Conservation Biology 15: 1522-1528.

Hobbs, R., \& C. Yates. 2003. Impacts of ecosystem fragmentation on plant populations: generalizing the idiosyncratic. Austral. J. Bot. 51: 471-488.

Parkes, D., G. Newell \& D. Cheal. 2003. Asessing the quality of native vegetation: the 'habitat hectares' approach. Ecol. Manag. Restor. 4: 29-38.

Rasmussen, H. 2002. Recent developments in the study of orchid mycorrhiza. Pl. Soil 244: 149-163.

Stenhouse, R. 2005. Ecology and Management of Bushland in Australian Cities. PhD thesis, University of Western Australia.

Western Australian Government. 2006. Wildlife Conservation (Rare Flora) Notice 2006(2). Western Australian Government Gazette 2006. Perth, Western Australia.

Belinda Newman was educated at Murdoch University, Perth, Australia, where she received a Bachelor of Environmental Science. She is currently completing a Ph.D. in environmental science from Murdoch University, looking at the ecology of orchids in urban bushland remnants and their use as indicators of vegetation condition. Belinda's research interests include vegetation condition and ecosystem health, effects of disturbance on orchid populations and orchid pollination.

Phil Ladd is a senior lecturer in ecology at Murdoch University, Perth, Australia. He is particularly interested in pollination ecology, community ecology and population biology. Phil is also interested in all aspects of palaeobotany including palynology and past vegetation history and the reconstruction of paleaoclimates based on vegetation reconstruction. Current research involves pollination ecology in buzz pollinated Western Australian natives and the conservation of the rare plant Lambertia orbifolia.

Andrew Batty recieved his Ph.D in 2001 specializing in the role of symbiotic seed germination and seed ecology in the conservation of selected Western Australian terrestrial orchids. His research interests include conservation biology of rare orchids and he has worked on the Millenium Seed Bank Project.

Kingsley Dixon has over 20 years experience in researching the ecology and physiology of Australian native plants and ecosystems. He leads a science group comprising botanical and restoration sciences and, as Director of Science at the Botanic Gardens and Parks Authority (BGPA), has developed a strong multi-disciplinary approach to conservation and restoration of native plant biodiversity and degraded landscapes. This research group has contributed significantly to seed science in Australia, with major advances in understanding seed dormancy as well as orchid seed conservation. 